\title{
Inhibition of Fatty Acid Binding Protein 4 in Obese Male Mice has Adversely Affected Reproductive Parameters
}

\section{Balci T ${ }^{1 *}$, Kocabas $\mathbf{R}^{2}$, Cuce $\mathrm{G}^{3}$ and Akoz $\mathbf{M}^{4}$}

${ }^{1}$ Ömer Halisdemir University, Education and Research Hospital, Turkey

${ }^{2}$ Department of KONUDAM Experimental Medicine Application and Research Center, Necmettin Erbakan University, Turkey

${ }^{3}$ Department of Histology and Embriology, Faculty of Meram Medicine, Necmettin Erbakan University, Turkey

${ }^{4}$ Department of Biochemistry, Faculty of Meram Medicine, Necmettin Erbakan University, Turkey

*Corresponding author: Balci Tevfik, MD, Ömer Halisdemir University, Education and Research Hospital, 51100 Niğde, Turkey, Tel: +90 (388) 23220 20; Fax: +90 (388) 212 14 11; Email: balcitevfik86@gmail.com

\section{Abstract}

Objective: BMS309403 (A drug) is a specific inhibitor of fatty acid binding protein 4. In this study, the effects of the BMS309403 on biochemical markers, testis tissue spermatogenesis and apoptotic markers were investigated in male mice.

Methods: Balb/c mice (total=56, each group $\mathrm{n}=14$ ) were divided into control, obese control, obese solvent and obese drug groups. The obese control, obese solvent and obese drug groups were fed on the high sucrose diet to lead to obesity. After the development of obesity, BMS309403 was orally administered to the obese drug group for six weeks.

Results: Serum fatty acid binding protein 4 levels were higher in obese control group and obese solvent group, compared to control $(\mathrm{p}<0.05)$ and obese drug groups $(\mathrm{p}<0.001)$. Serum total testosterone, free androgen index, inhibin-B, sex hormone binding globulin levels, testicular tissue B-cell lymphoma-2 expression level and Johnson Score parameters were lower in all obese groups compared with the control group. Inhibin-B levels and Johnson Score results were lower in obese drug group compared to other two obese groups $(\mathrm{p}<0.05)$.

Conclusion: Contrary to expectations, the use of BMS309403 negatively affected male reproductive parameters. Negative changes in reproductive parameters may be a result of the increased lee index of obesity.

Keywords: BMS309403; Male fertility impairment; Side-effect; experimental obesity; Fatty acid binding protein 4; Mice

\section{Introduction}

Today, obesity has almost become an epidemic that affects about 2 billion people in total; about 1.6 billion adults are overweight and 400 million adults are classified as obese $[1,2]$. Obesity may affect both the quality of our life and it might cause a number of diseases [3]. In the treatment of obesity, it is also important and necessary to treat complications that are caused by obesity as well as obesity itself [4].

Many studies in recent years have shown that embryo development and in turn pregnancy is adversely affected by maternal obesity-induced oocyte changes. The effects of paternal obesity on embryo development and pregnancy 


\section{International Journal of Biochemistry \& Physiology}

have been investigated only in the last 2 to 3 years. Recently, it is reported that the female and male partners are equally responsible for the adverse effects of obesity on embryo development and pregnancy [2].

Fatty Acid Binding Protein 4 (FABP4) is a recently defined lipid-derived molecule that is involved in the transport of lipids and other hydrophobic molecules between intracellular and extracellular domains. Positive correlations exist between serum FABP4 levels, and markers of metabolic syndrome and vascular disease have been reported in various studies. As a result of studies with FABP4 knockout and FABP4 inhibitor-administered mice, FABP4 has been reported to have therapeutic effects on obesity associated with atherosclerosis, hypertriglyceridemia and insulin resistance [4].

The drug called BMS309403 is a specific inhibitor of FABP4 and inhibits the effect of FABP4 as a competitive hydrophobic ligand [5]. Experimental studies have revealed protective effects of the drug against obesity and the development of obesity-induced complications such as atherosclerosis, hyperlipidemia, insulin resistance, and fatty liver disease [6,7].

The aim of our study was to investigate the effects of the drug BMS309403 on male fertility disorder, a common complication of obesity. In line with this goal in the project, obesity was established in male mice, and the histological examination of spermatogenesis status, apoptosis markers B-cell lymphoma - 2 (BCL-2), BCL-2 related protein X (BAX) protein expressions and DNA integrity of testis tissue were examined. In addition to the tissue study, total testosterone, sex hormone binding globulin (SHBG), inhibin-B and FABP4 protein levels were analyzed in serum.

\section{Materials and Methods}

\section{Experimental animals}

This study was approved by the Necmettin Erbakan University, KONUDAM Experimental Medicine Application and Research Center's Experimental Animal Ethics Committee (No: 2014-057). A total of 40 male Balb/c mice (16-19 g: 63 days old) were used. The mice were housed in a room with an average temperature of $20^{\circ} \mathrm{C}$, approximately $50 \%$ relative humidity, ventilated 15 times per hour, in $12 / 12$ hours light- dark period. All groups were fed the same standard mouse chow.

\section{Experimental Design}

After a 1-week acclimation period, animals were randomly divided into four groups: $1^{\text {st }}$ as control group (CG, $n: 10), 2^{\text {nd }}$ as obese control group (OCG, n:10), $3^{\text {rd }}$ as obese solvent group (OSG, n:10), and $4^{\text {th }}$ as obese drug group (ODG, $\mathrm{n}: 10)$. All of the mice were weighed at the beginning of the study and the Lee Index of Obesity (LIO) was calculated [8]. Then, The OCG, OSG, and ODG were fed with a high sucrose diet from the beginning to the end of the study. The development of obesity in the mice was evaluated by monitoring LIO every 2 weeks. When the LIO was greater than 0.3 , the mice were considered obese [9]. At the beginning of the $10^{\text {th }}$ week, it was determined that all the mice in the OCG, OSG, and ODG had LIO: $\geq 0.3$ (Table 1). After this, BMS309403 (15 mg/kg/day) and a solvent of BMS309403 (DMSO) were administered to the ODG and to the OSG respectively by oral gavage for five weeks $[6,10]$.

\section{Preparation of High Sucrose Diet and BMS30940}

$30 \%(\mathrm{v} / \mathrm{v}$ ) liquid sucrose (Sunar Misir integrated Industry $\mathrm{Co}$ ) was added to the drinking water (DW) $[11,12]$. BMS309403 (Cayman Chemical Co, cas No: 300657-03-08) was dissolved in Dimethyl sulfoxide (DMSO, Sigma-Aldrich Chemical Co, cas No: 67-68-5).

\section{Biochemical Analysis}

At the end of the $14^{\text {th }}$ week, the nutrition of all groups was stopped at 7:00 am and euthanasia was performed with exsanguination under anesthesia (50 mg. $\mathrm{kg}^{-1}$ ketamine / 10 mg.kg-1 xylazine) at 1:00 pm. Blood samples taken from the heart were transferred to biochemical tubes with gel and clot activator, allowed to clot at room temperature for 30 minutes and then were performed as described [13].

Total testosterone (cat no: YHB1275Mo), SHBG (cat no: YHB1208Mo), FABP4 (cat no: YHB1491Mo) and inhibin-B (cat no: YHB0749Mo) tests were performed in serum through ELISA method (Yehua Biological Technology Co.) Free androgen index (FAI) values were calculated as described [14].

\section{Tissue Analysis}

Testis sections were stained with Hematoxylin-Eosin and quantitatively assessed through Johnson Score for spermatogenesis and germ cell health. In addition, TUNELpositive cell counts (Apoptag in situ apoptosis detection kit, Sigma-Aldrich Chemical Co.), BCL-2 and BAX (Abcam Chemical Company, cat. no. ab7973, cat. no. ab7977; respectively) expression measurements were performed through immunohistochemical methods to evaluate apoptosis. 


\section{International Journal of Biochemistry \& Physiology}

\section{Statistical Analysis}

The data obtained were statistically evaluated using the Statistical Package for the Social Sciences version 16.0 program. The ANOVA-Tukey HSD test was applied to the TUNEL method and the Johnson Score. Weight and LIO parameters were analyzed through ANOVA in repeated measures. It was checked through Mauchly's Test of Sphericity, Bonferroni correction and Dunnett test. The Mann-Whitney $\mathrm{U}$ test (FABP4, total testosterone, Inhibin-B, SHBG, FAI, BAX, and BCL-2) was applied in a binary comparison between the groups. The value of $\mathrm{p}<0.05$ was considered statistically significant.

\section{Results}

\section{The Body Weight and LIO}

In the OCG, OSG, ODG obesity developed from the $9^{\text {th }}$ week onwards (LIO $\geq 0.3$ ). At the end of the $6^{\text {th }}$ week, there was a significant increase in the body weight (BW) of the OCG, OSG, and ODG according to the CG (Table 1).

\begin{tabular}{|c|c|c|c|c|c|}
\hline Groups & BW/LIO & Initial & 6th week & 9th week & 15th week \\
\hline \multirow{2}{*}{ CG } & BW (g) & $17.29 \pm 1.19$ & $19.81 \pm 1.08$ & $21.74 \pm 1.03$ & $23.16 \pm 0.99$ \\
\cline { 2 - 6 } & LIO & $0.260 \pm 0.008$ & $0.268 \pm 0.009$ & $0.274 \pm 0.005$ & $0.277 \pm 0.004$ \\
\hline \multirow{2}{*}{ OCG } & BW (g) & $17.20 \pm 0.78$ & $24.18 \pm 0.81^{\mathrm{a}}$ & $27.46 \pm 0.64^{\mathrm{a}}$ & $32.24 \pm 0.91^{\mathrm{a}}$ \\
\cline { 2 - 6 } & LIO & $0.269 \pm 0.004$ & $0.294 \pm 0.005^{\mathrm{a}}$ & $0.304 \pm 0.005^{\mathrm{a}}$ & $0.316 \pm 0.005^{\mathrm{a}}$ \\
\hline \multirow{2}{*}{ OSG } & BW (g) & $16.90 \pm 0.8$ & $23.98 \pm 0.89^{\mathrm{a}}$ & $27.75 \pm 0.76^{\mathrm{a}}$ & $31.83 \pm 0.88^{\mathrm{a}}$ \\
\cline { 2 - 6 } & LIO & $0.266 \pm 0.005$ & $0.291 \pm 0.003^{\mathrm{a}}$ & $0.302 \pm 0.005^{\mathrm{a}}$ & $0.312 \pm 0.004^{\mathrm{a}}$ \\
\hline \multirow{2}{*}{ ODG } & BW (g) & $17.06 \pm 0.69$ & $24.05 \pm 0.81^{\mathrm{a}}$ & $28.10 \pm 0.73^{\mathrm{a}}$ & $34.48 \pm 1.25^{\mathrm{a}, \mathrm{b}}$ \\
\cline { 2 - 6 } & LIO & $0.262 \pm 0.006$ & $0.288 \pm 0.006^{\mathrm{a}}$ & $0.301 \pm 0.003^{\mathrm{a}}$ & $0.320 \pm 0.007^{\mathrm{a}}$ \\
\hline
\end{tabular}

Table 1: The body weight (BW) and Lee Index of Obesity (LOI) measurement results (mean \pm SD).

*Statistical evaluation between the groups (according to CG ap $<0.001$ and according to OSG $b p=0.003$ ).

\section{FABP4, Total Testosterone, FAI, Inhibin-B and SHBG}

Serum total testosterone, FAI, inhibin-B, and SHBG values were significantly lower in the all obese groups than in the CG. In addition, serum inhibin-B value in the ODG was significantly lower than in the OCG and OSG. Serum FABP4 value was found to be higher in the OCG and OSG compared to the CG and ODG (Table 2).

\begin{tabular}{|c|c|c|c|c|c|}
\hline Groups & Groups (ng/mL) & $\begin{array}{c}\text { Total testosterone } \\
\text { (nmol/L) }\end{array}$ & FAI & $\begin{array}{c}\text { Inhibin-B } \\
\text { (ng/L) }\end{array}$ & SHBG (nmol/L) \\
\hline CG & $0.347(0.208)$ & $8.411(1.712)$ & $83.131(22.73)$ & $36.148(13.15)$ & $9.84(1.08)$ \\
\hline OCG & $0.496(0.118)^{a}$ & $5.722(3.016)^{a}$ & $67.024(15.39)^{a}$ & $29.007(11.21)^{a}$ & $7.734(3.08)^{a}$ \\
\hline OSG & $0.513(0.136)^{a}$ & $4.561(1.952)^{b}$ & $71.716(32.67)^{a}$ & $26.758(12.77)^{a}$ & $7.237(2.70) b$ \\
\hline ODG & $0.306(0.149)^{a, e, g}$ & $4.093(0.818)^{c}$ & $56.587(23.66) c$ & $19.59(8.90)^{c, d, f}$ & $7.368(3.29)^{a}$ \\
\hline
\end{tabular}

Table 2: Median and interquartile range values of biochemical parameters.

* Statistical evaluation between the groups (according to $C G{ }^{a} p<0.05$, ${ }^{b} p<0.01$, ${ }^{c} p<0.001$; according to OCG ${ }^{d} p<0.05$, ${ }^{e} p<0.001$; according to OSG ${ }^{\mathrm{f}} \mathrm{p}<0.05,{ }^{\mathrm{g}} \mathrm{p}<0.001$ ).

\section{Johnson Score and Apoptosis Markers}

The BAX parameter increased in all obese groups compared to the $\mathrm{CG}$, and the BCL-2 parameter was significantly lower in all obese groups than in the CG $(p<$
0.05). The Johnson Score was lower in the all obese groups than in the CG $(\mathrm{p}<0.05)$. The number of TUNEL-positive staining cells was found to be higher in the all obese groups than in the CG $(\mathrm{p}<0.05)$, and the other results were given in table 3 . 


\section{International Journal of Biochemistry \& Physiology}

\begin{tabular}{|c|c|c|c|c|c|c|c|c|}
\hline \multirow{2}{*}{ Groups } & \multicolumn{3}{|c|}{ BAX positive } & \multicolumn{3}{|c|}{ BCL-2 positive } & \multirow{2}{*}{$\begin{array}{c}\text { TUNEL } \\
\text { Positive }\end{array}$} & \multirow{2}{*}{$\begin{array}{c}\text { Johnson } \\
\text { score }\end{array}$} \\
\hline & $25 \%$ & $50 \%$ & $75 \%$ & $25 \%$ & $50 \%$ & $75 \%$ & & \\
\hline CG & 0 & 0 & 1 & 3 & 3 & 3 & $0.14 \pm 0.03^{a}$ & $9.52 \pm 0.17^{\mathrm{a}}$ \\
\hline OCG & 2 & 2 & 3 & 0 & 1 & 1 & $0.26 \pm 0.05^{b, c}$ & $6.88 \pm 0.12^{b}$ \\
\hline OSG & 2 & 2 & 3 & 1 & 1 & 1 & $0.25 \pm 0.06^{\mathrm{b}}$ & $7.05 \pm 0.22^{b}$ \\
\hline ODG & 2 & 3 & 3 & 0 & 1 & 1 & $0.34 \pm 0.04^{c}$ & $6.64 \pm 0.05^{c}$ \\
\hline
\end{tabular}

Table 3: Median (50\%) and interquartile range values of BAX, BCL-2 positive cells of groups.

$*$ Johnson Score and TUNEL method (mean \pm SD). Different superscripts in the same columns indicate a significant difference $\left({ }^{a-c} \mathrm{p}<0.05\right)$.

The results of BAX immunohistochemical staining revealed a significant difference between the groups $(\mathrm{p}=$ 0.001). A significant increase was detected between the CGOCG, CG-OSG and CG-ODG groups. BAX expression increased in OCG, OSG and ODG groups compared to CG group. There was no difference between the other group comparisons.

There was a significant difference between the groups of Kruskal Wallis test for BCL-2 immunohistochemical staining $(p=0.001)$. A significant decrease was detected between the groups of CG-OCG, CG-OSG and CG-ODG groups according to the results of the Man-Whitney $U$ test. BCL-2 expression decreased in OCG, OSG and ODG groups compared to CG group. There was no difference between the other group comparisons.

BAX and BCL-2 expressions in the testis sections of the groups, TUNEL-positive stained cells and staining with Hematoxylin-Eosin for Johnsen score are shown in figures $1-4$ respectively.

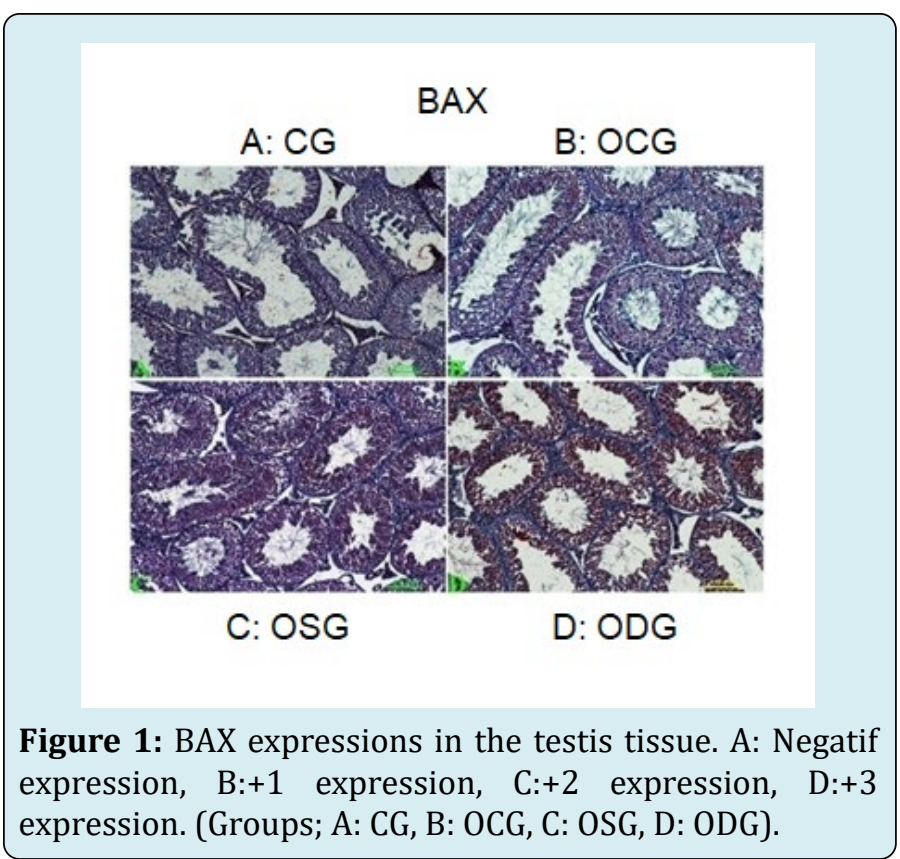

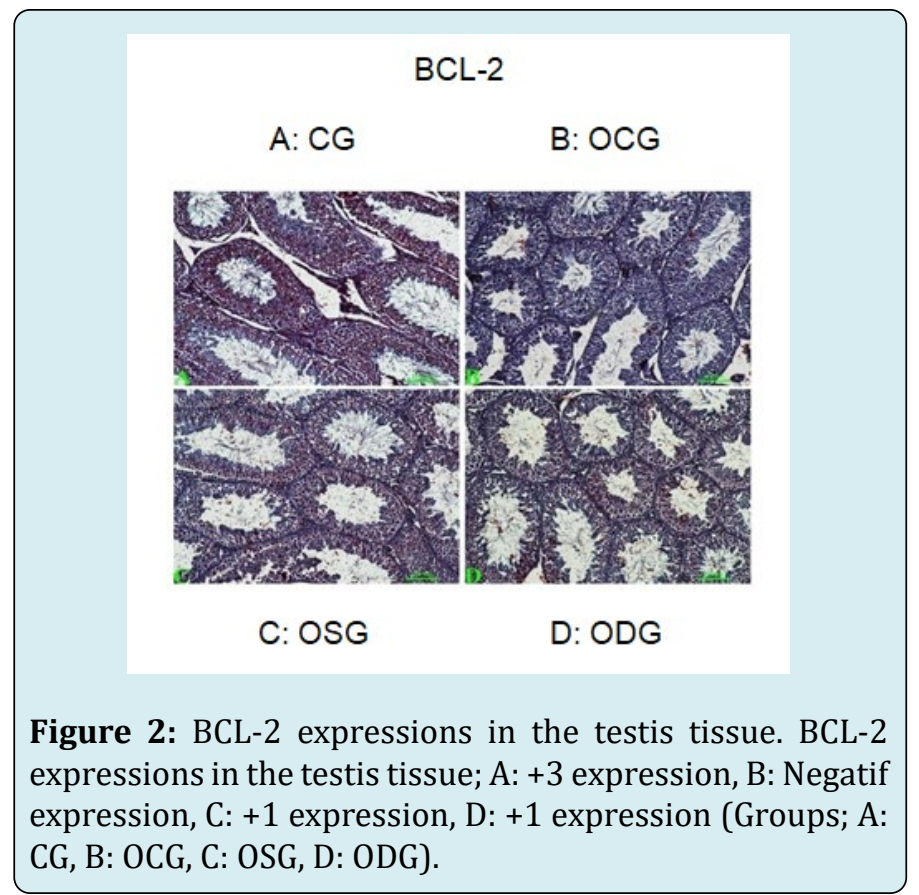

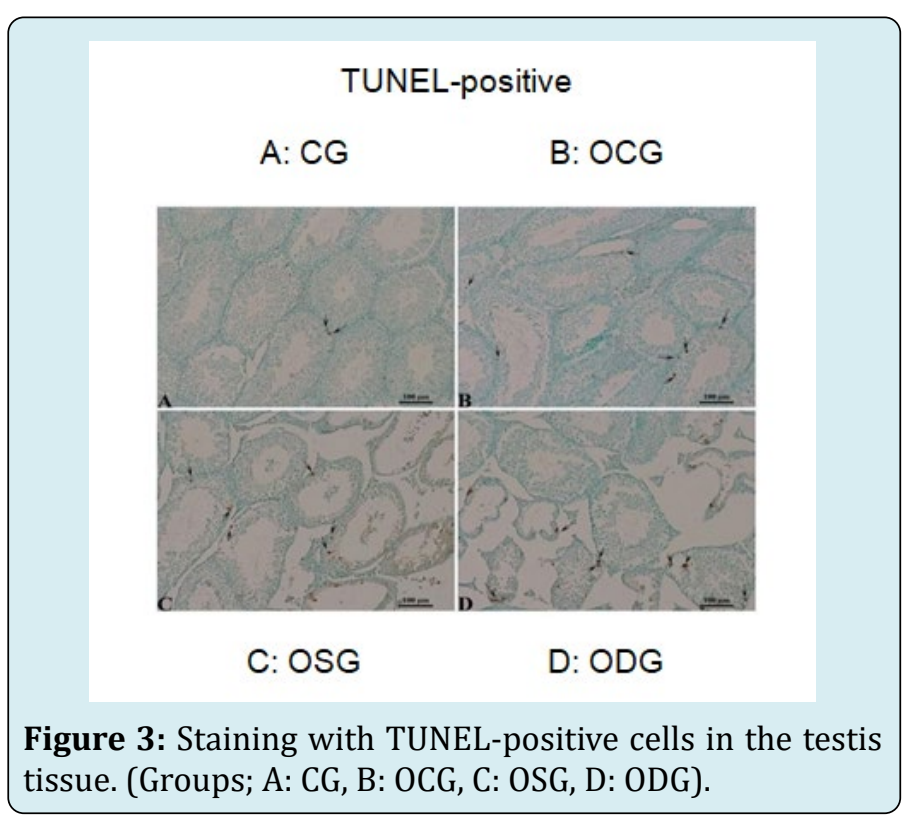




\section{International Journal of Biochemistry \& Physiology}

\section{$A: C G$ \\ B: OCG}
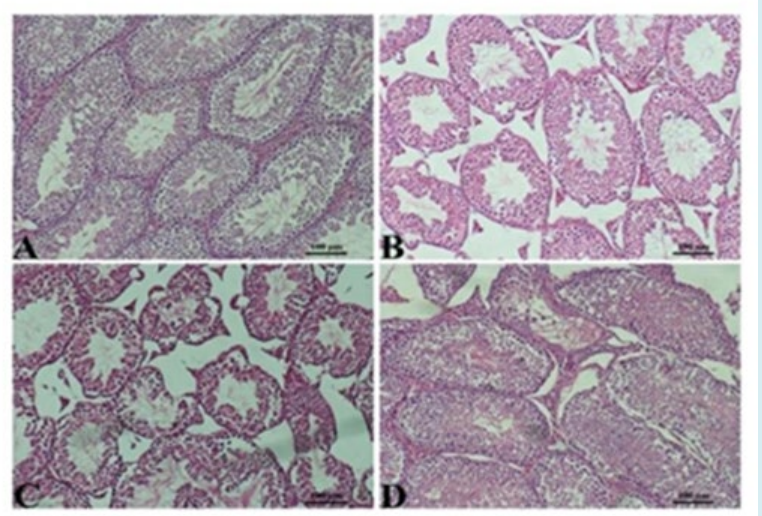

C: OSG

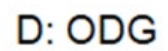

Figure 4: Hematoxylin-Eosin in the testis tissue. (Groups; A: CG, B: OCG, C: OSG, D: ODG).

DMSO is a commonly used lipophilic drug carrier that can penetrate almost all the cells without harming the skin and membranes [15]. There was no positive or negative effect of DMSO, which we used as a BMS309403 solvent in the study (OSG group), on obesity and fertility.

\section{Discussion}

In this study, the effects of BMS309403 on male fertility disorders which are one of the complications of obesity have been investigated. Moreover, histological evaluations have been examined in the testicular tissue.

In our study, BMS309403 was administered to mice with diet-induced obesity. This administration led to a higher BW increase than the OCG in the ODG. The reason for BW increase in the ODG may be the inhibition of lipolysis and the increase in adipogenesis as a result of FABP4 inhibition [14]. Thus, our findings are consistent with studies investigating the effects of BMS309403 due to inhibition of FABP4 $[4,16]$.

FABP4 expression is enhanced by insulin, fatty acids, dexamethasone, and peroxisome proliferator-activated receptor gamma (PPAR $\gamma$ ) activation as a marker of adipocyte differentiation. Evidence from genetic mouse models suggests that PPAR $\gamma$ directly increases FABP4 gene expression, while FABP4 decreases PPAR $\gamma$ activity [17]. FABP4 regulates cholesterol efflux in macrophages by inhibiting the PPAR $\gamma$ / liver X receptor- $\alpha$ / ATP binding cassette transporter A1 pathway and contributes to foam cell formation [18]. In the absence of FABP4 in mice, the production and function of many proinflammatory cytokines (Tumor necrosis factor $\alpha$, interleukin $1 \beta$, interleukin-6, Monocyte chemoattractant protein-1) and proinflammatory enzymes (inducible nitric oxide synthase, cyclooxygenase-2) decreased in macrophages. However, in studies conducted in humans, the number of studies in which similar results are obtained is fewer [19]. In studies in which FABP4 inhibition was genetically and pharmacologically studied in diabetic obese mice, the inhibition of FABP4 is shown to increase weight gain as opposed to no weight-reducing action. However, it is also shown to reduce the development of obesity-related complications such as insulin resistance, Type 2 diabetes mellitus, and atherosclerosis [16].

Deprivation of FABP4 significantly affects two major metabolic processes. The first is the reduction of nonesterifying fatty acid release from fat tissue, and the second is the increase in the use of glucose in tissues instead of fatty acids [20]. Obesity complications may be due to lipid molecules, such as long-chain free fatty acids, rather than increased fat mass [21]. This suggests that treatment methods targeting FABP4 may be effective on secondary metabolic and inflammatory complications of obesity rather than the obesity itself.

In obesity, increased peripheral testosterone-estradiol conversion due to increased peripheral fat tissue (through the high amount of aromatase enzyme in the fat tissue) may cause hypothalamic-hypophyseal-gonadal axis disturbance and secondary hypogonadism [2]. In the suprapubic and scrotal region, increased fat tissue may impair spermatogenesis by raising the testicular temperature. Besides, leptin levels which rise along with increasing fat tissue in obesity may reduce testicular testosterone production [22-24]. Due to increased obesity-related DNA fragmentation index and increased reactive oxygen radicals, there may be a decrease in sperm quantity and quality [22]. Consequently, erectile dysfunction may develop [25]. It has been found that male fertility markers (serum total testosterone, FAI, inhibin-B, and SHBG) were significantly lower in obese groups (especially in the ODG) than in the CG (Table 2).

In obese males, fertility impairment can't be determined by only examining sperm quality by spermiogram method, but also physical and molecular structure of germ cells and the morphological state of sperm cells should be considered at different maturation stages [2]. We evaluated this condition with apoptosis markers and Johnsen score, and the lowest Johnsen score in the all groups was found in the ODG (Table 3, Figures 1 \& 2). Our data comply with the data presented by Palmer, et al [2]. In all these findings, we think that proapoptotic processes may be induced in experimental obesity in the testis, that Johnsen Score may be reduced, and that BMS309403 administration does not have any healing effects on these processes; on the contrary, it increases apoptosis. 


\section{International Journal of Biochemistry \& Physiology}

When all the parameters (biochemical and histological) in our study were evaluated together, it was observed that BMS309403 administration to obese male mice increased pro-apoptotic processes and spermatogenesis disorder and also caused decreases in sex hormone levels (Tables 1-3, Figures 1-4). BMS309403 leads to an increase in LIO, and as a result, negative changes in reproductive parameters may be developed, accompanied by the increasing LIO.

\section{Conclusion}

It is observed in our findings that the use of BMS309403 did not have any beneficial effects on male fertility, but on the contrary, there may be adverse effects. We think that these adverse effects may be related to the increase in BW and also to the increase in obesity by delivery of BMS309403 to the ODG.

\section{References}

1. Ng M, Fleming T, Robinson M, Thomson B, Graetz N, et al. (2014) Global, regional, and national prevalence of overweight and obesity in children and adults during 1980-2013: A systematic analysis for the Global Burden of Disease Study. Lancet 384(9945): 766-781.

2. Palmer NO, Bakos HW, Fullston T, Lane M (2012) Impact of obesity on male fertility, sperm function and molecular composition. Spermatogenesis 2(4): 253-263.

3. Youngson NA, Whitelaw E (2011) The effects of acquired paternal obesity on the next generation. Asian J Androl 13(2): 195-196.

4. Kralisch S, Fasshauer M (2013) Adipocyte fatty acid binding protein: A novel adipokine involved in the pathogenesis of metabolic and vascular disease? Diabetologia 56(1): 10-21.

5. Okada T, Hiromura M, Otsuka M, Enomoto S, Miyachi $\mathrm{H}$ (2012) Synthesis of BMS-309403- Related Compounds, Including [14C]BMS-309403, a Radioligand for Adipocyte Fatty Acid Binding Protein. Chem Pharm Bull (Tokyo) 60(1): 164-168.

6. Furuhashi M, Tuncman G, Görgün CZ, Makowski L, Atsumi G, et al. (2007) Treatment of diabetes and atherosclerosis by inhibiting fatty-acid-binding protein aP2. Nature 447(7147): 959-65.

7. Suhre K, Römisch-Margl W, De Angelis MH, Adamski J, Luippold G, et al. (2011) Identification of a potential biomarker for FABP4 inhibition: The power of lipidomics in preclinical drug testing. J Biomol Screen 16(5): 467475.
8. Plocher TA, Powley TL (1997) Maintenance of obesity following hypophysectomy in the obese hyperglycemic mouse (ob/ob). Yale J Biol Med 50(3): 291-300.

9. Hilwani IN, Nasibah R, Nurdiana S, Norashirene MJ (2014) Gonadotoxic and Cytotoxic Effect of Induced obesity via Monosodium Glutamate on Mus musculus Testis Cytoarchitecture and Sperm Parameter. International Journal of Agricultural and Biosystems Engineering 8(9): 1000-1003.

10. Lee CG, Da Silva CA, Dela Cruz CS, Ahangari F, Ma B, et al. (2011) Role of Chitin and Chitinase/Chitinase-Like Proteins in Inflammation, Tissue Remodeling, and Injury. Annu Rev Physiol 73: 479-501.

11. Novelli EL, Diniz YS, Galhardi CM, Ebaid GM (2007) Rodrigues HG, Mani F, et al. Anthropometrical parameters and markers of obesity in rats. Lab Anim 41(1): 111-119.

12. Ritze Y, Bárdos G, D’Haese JG, Ernst B, Thurnheer M, et al. (2014) Effect of high sugar intake on glucose transporter and weight regulating hormones in mice and humans. PLoS One 9(7): e101702.

13. Kocabaş R, Aköz M (2018) The effects of vitamin D supplementation on healthy and hypercholesterolemic rabbits on levels of OSI and paraoxonase. Turk J Biochem 43(5): 549-556.

14. Al Kindi MK, Al Essry FS, Al Essry FS, Mula-Abed WA (2012) Validity of serum testosterone, free androgen index, and calculated free testosterone in women with suspected hyperandrogenism. Oman Med J 27(6): 471474.

15. Cai WJ, Huang JH, Zhang SQ, Wu B, Kapahi P, et al. (2011) Icariin and its derivative icariside II extend healthspan via insulin/IGF-1 pathway in C. elegans. PLoS One 6(12): e28835.

16. Yang R, Castriota G, Chen Y, Cleary MA, Ellsworth K, Shin MK, et al. (2011) RNAi-mediated germline knockdown of FABP4 increases body weight but does not improve the deranged nutrient metabolism of diet-induced obese mice. Int J Obes 35(2): 217-225.

17. Hotamisligil GS, Bernlohr DA (2015) Metabolic functions of FABPs - Mechanisms and therapeutic implications. Nat Rev Endocrinol 11(10): 592-605.

18. Makowski L, Brittingham KC, Reynolds JM, Suttles J, Hotamisligil GS (2005) The fatty acid- binding protein, aP2, coordinates macrophage cholesterol trafficking and inflammatory activity: Macrophage expression of aP2 impacts peroxisome proliferator-activated receptor $\gamma$ 


\section{International Journal of Biochemistry \& Physiology}

and IкB kinase activities. J Biol Chem 280(13): 1288812895.

19. Bourlier V, Bouloumie A (2009) Role of macrophage tissue infiltration in obesity and insulin resistance. Diabetes Metab 35(4): 251-260.

20. Baar RA, Dingfelder CS, Smith LA, Bernlohr DA, Wu C, et al. (2005) Investigation of in vivo fatty acid metabolism in AFABP/aP2(-/-) mice. Am J Physiol Endocrinol Metab 288(1): E187-93.

21. Uysal KT, Scheja L, Wiesbrock SM, Bonner-Weir S, Hotamisligil GS (2000) Improved glucose and lipid metabolism in genetically obese mice lacking aP2.
Endocrinology 141(9): 3388-3396.

22. Kasturi SS, Tannir J, Brannigan RE (2009) The metabolic syndrome and male infertility. J Androl 29(3): 251-259.

23. Pinilla L, Seoane LM, Gonzalez L, Carro E, Aguilar E, et al. (1999) Regulation of serum leptin levels by gonadal function in rats. Eur J Endocrinol 140(5): 468-473.

24. Wang C, McDonald V, Leung A, Superlano L, Berman N, et al. (1997) Effect of increased scrotal temperature on sperm production in normal men. Fertil Steril 68(2): 334-339.

25. Chambers TJ, Richard RA (2015) The impact of obesity on male fertility. Hormones 14(4): 563-568. 